\title{
Review of benchmark on-grid power tariffs in China
}

\author{
Liang $\mathrm{Han}^{1,{ }^{*}}$, Yuou Hu${ }^{1}$, Tao Zhang ${ }^{1}$, Jing Zhang ${ }^{1}$, Zijun $\mathrm{Tu}^{2}$ and Yuguo Chen ${ }^{2}$ \\ ${ }^{1}$ North China Branch of State Grid Corporation of China, 100053 Beijing, China \\ ${ }^{2}$ Beijing Tsintergy Technology Co., Ltd, 100084 Beijing, China
}

\begin{abstract}
This paper reviews the introduction, implementation, and adjustment of benchmark on-grid power tariffs in China as well as discusses the impact from the on-going power market reforms. The analysis was made with the price data and policy documents from the NDRC and regional regulators. This paper concludes with a summary of features and drivers of historical changes in benchmark on-grid power tariffs and the values and contributions of this dominant price-setting mechanism of electric power in the last 15 years.
\end{abstract}

\section{Introduction}

Electricity power is a specialized industry product, but the difference with all other products is that electricity cannot be freely stored, which means electricity is produced in real-time, consumed in real-time, and dynamically balanced. Before the 1990s, the power industry worldwide was regulated, and the utilities own and operate the whole value chain [1]. The main task of electricity prices is to cover the cost of building, finance, maintaining, and operating power plants and the electricity grid. In order to reduce the price fluctuations for consumers and guarantee a stable revenue for power suppliers, the electricity price was worldwide strictly regulated until the USA, and some European countries start to deregulate its electricity industry in the 1990s. After that, a more market-oriented price mechanism had been introduced [2].

Since 1985, China has adjusted the electricity price policies many times according to the changes of the relationship between electricity supply and demand [3]. The regulated prices were calculated based mainly on fuel price, finance cost, and operation-period of power plants or the levelized life cycle cost of energy. These regulated price mechanisms promoted the investment in power infrastructure so that the generation capacity could meet the rapidly increasing electricity demand that came with China's fast economic growth. Along with all the price policies, benchmark on-grid power tariffs have a dominant influence on the power industry's development and investment. The whole price mechanism was first officially initiated in the "Plan of Electric Industry Reform" in December 2002 [4]. The on-grid power prices are composed of the government's capacity prices and the electricity prices generated by market bidding. The government determines the transmission and distribution prices. The retail prices are formed based on the above electricity prices, and a mechanism for linkage with the on-grid power price is established. Since then, a threestage electricity price system has been formed consisting of on-grid power prices, transmission and distribution prices, and retail prices [5].

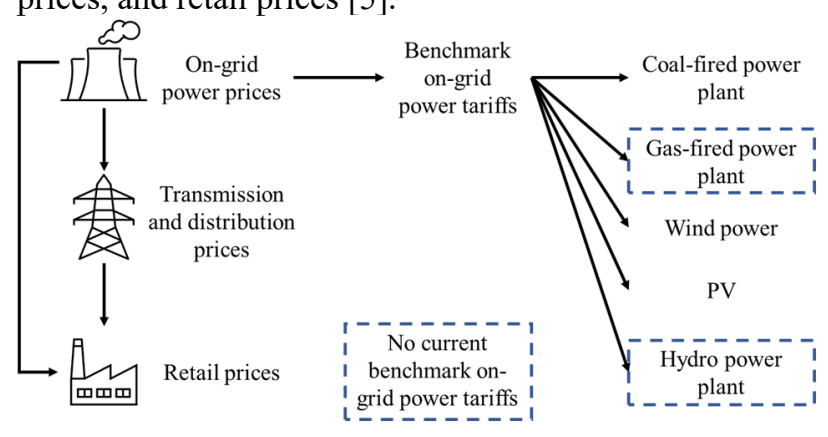

Fig1. Three-stage electricity price system

From the on-grid power prices, a new tariff-setting policy was implemented in 2004, which introduced the benchmark on-grid power tariffs. This tariff was born of operation-period tariff and based on regional or provincial average generation costs. It is the fundamental of the current electricity price system and the core financing indicator of power portfolio investment [5].

However, this top-down tariff-setting mechanism also has some limitations. China's power industry moves into a new era with an increasing overcapacity since 2010[3]. In order to introduce a market-oriented price system to optimize the allocation of resources, the central government of China launched a new market reform of its power industry in March 2015, following the release of the document "Several opinions on further deepening the reform of the power system" to build a "complete, open, orderly and competitive" power market system [6].

Some researches were done to analyse the development and reform of on-grid power tariffs before 2012 [5]. But the impact of the new power market reform process in China was not taken into account. This paper aims to review the price development and the policy change of benchmark on-grid power tariffs from 2005 to 2020 of different generation technologies based on onehand data from the National Energy Administration.

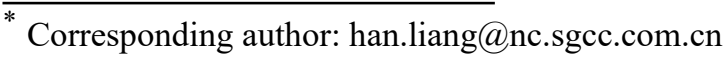




\section{General policy development of benchmark on-grid power tariffs}

Benchmark on-grid power tariffs is an achievement of the first round of power system reform started in 2002. According to the so-called Document No. 5, the price reform's objective is to comprehensively introduce a competition mechanism, and prices are formed by competition between supply and demand parties. The supplementary documents for the reform of electricity tariffs were first issued in July 2003 and the detailed rules for the tariff-setting were released in March 2005 in "Implementation Measures for Electricity Price Reform" [7], which defines a clear position of benchmark on-grid power tariffs: Before a market-based pricing system for generation is fully implemented, all newly constructed generation units in the same region should use the same on-grid price i.e., the benchmark on-grid power tariff, which should be announced to the public in advance.

The benchmark on-grid power tariffs for coal-fired power plants was already announced in April 2004 by NDRC [8]. In June 2004, six regulation documents regarding the tariff-setting in six regions were announced and the benchmark on-grid power tariffs for every province were determined. The benchmark on-grid tariffs in different regions and provinces were set to represent the difference in energy and economic development and the fuel resources allocation in different provinces. In the meantime, a special policy about coal and electricity price linkage mechanism was established in 2004 aimed to resolve the conflict between the fully regulated power tariffs of coal fired power plant and the partly liberalised coal market [9]. According to the new policy, the benchmark on-grid power tariffs for coal fired power plants increase corresponding to coal price. This policy significantly impacts the general benchmark on-grid power tariffs because the tariffs of another generation technologies also reflect on the tariffs of coal fired power plants. A detailed analysis could be found in chapter 3.1.

With the continuous development of the renewable energies, policies for benchmark on-grid power tariffs of renewable energies were introduced since 2006 [10]. After 2009, newly built PV and Wind power assets get fixed ongrid tariffs for a predefined time, which are usually called feed-in tariffs. These specific tariffs could be determined by biding or tendering. The tariff-setting mechanism for hydropower plants, including pumped storage power plants, is more complicated and individual. The hydropower plants which supply power only for their province have the standard benchmark on-grid tariffs. Besides, for those assets built in a region with abundant water resources, a special tariff for different seasons was used. The price of hydropower for inter-provincial and cross-regional transmission is negotiated between the supply and demand parties based on the receiving province's benchmark on-grid power tariff. Pumped storage power plants were also regulated by a new tariffsetting policy since 2014 . They get a capacity tariff that covers the investment with a risk-free yield (long-term treasury bond interest rate) plus 1-3\% and an energy tariff that covers the variable cost. This tariff-setting policy made pumped storage power plant a very attractive investment and secured the long-term return [11]. Since then, the framework of China's benchmark on-grid power tariff policy had been completed and entered the stage of gradual improvement and adjustment depending on different generation technologies.

In general, the introduction, implementation, and adjustment of benchmark on-grid power tariffs is an efficient policy instrument between a full regulated pricesetting mechanism and the comprehensive marketoriented price-setting mechanism.

\section{Adjustment of benchmark on-grid power tariffs of different generation technologies}

\subsection{Coal-fired power plant}

In 2004, the setting and adjustment of benchmark on-grid power tariffs of the coal-fired power plant were issued [9]. Based on coal and electricity price linkage mechanism, the benchmark on-grid power tariffs of coal-fired power plants national wide should be adjusted, when the average coal price in China increases by $5 \%$ within a half year, but only $70 \%$ of the increase will be passed to the on-grid power tariffs and the coal-fired power plants operator will bear the rest of $30 \%$. In 2013, the part which the generation companies should carry reduced from $30 \%$ to $10 \%$.

From 2004 to 2015, the benchmark tariffs should be adjusted 12 times according to the coal and electricity price linkage mechanism, including nine rises with a cumulative increase of $0.09936 \mathrm{RMB} / \mathrm{kWh}$ and three reductions with a cumulative decrease of 0.0433 $\mathrm{RMB} / \mathrm{kWh}$. But in fact, only three adjustments took place, including two rises with a cumulative increase of 0.03474 $\mathrm{RMB} / \mathrm{kWh}$ and one reduction with a decrease of 0.020 RMB/kWh. From 2016 to 2019, the benchmark tariffs were adjusted only once and were reduced by 0.030 $\mathrm{RMB} / \mathrm{kWh}$. At the beginning of 2018 , the coal price reached the limit, but no adjustment was made. Regardless of the tariff adjustments based on the change of coal prices, benchmark on-grid power tariffs of coal-fired power plants are generally lower than that of other nonrenewable generation technologies. The tariffs differ significantly in different regions. The on-grid tariffs in 2005 ranged between $0.2270 \mathrm{RMB} / \mathrm{kWh}$ and 0.4240 $\mathrm{RMB} / \mathrm{kWh}$ [8].

In 2019, four years after the beginning of the new power market reform, coal and electricity price linkage mechanism was cancelled, and the benchmark on-grid power tariffs is no more a fixed number but could be adjusted in a range. This policy's background is that more than $50 \%$ of the generated power was traded with marketoriented prices, which is usually lower than the benchmark tariffs. The abolition of the coal and electricity price linkage mechanism is also a part of the on-going power market reform. The change of the tariff-setting policy gives the whole industry more rooms for a marketoriented pricing finding mechanism. 


\subsection{Gas-fired power plant}

As a conventional generation technology, gas-fired power plants have more individual tariffs than coal-fired power plants. There are no general benchmark tariffs for gasfired power plant and tariffs for newly built assets are determined by the NDRC and is based on the function and operation time of the power plants. The tariffs for the gasfired power plant, which was built for peak shaving, is higher than that of the standard gas-fired power plant, which was close to $0.79 \mathrm{RMB} / \mathrm{kWh}$ [12].

\subsection{Wind power}

Since early 2009, the former concession tendering and guiding prices system could not fulfil the requirements of the increasing investments in the gradually maturing wind power industry. NDRC announced a feed-in tariff system for new onshore wind power projects in August 2009. The feed-in tariff has a similar function as benchmark on-grid power tariff. The only difference is that once the renewable energy asset is connected into the grid, the tariff would not be changed for a fixed time. The tariffs were sorted in four categories. Category I is applied for the assets in the region with the most abundant wind resources as the category IV is for the assets built in relatively fewer wind resources.

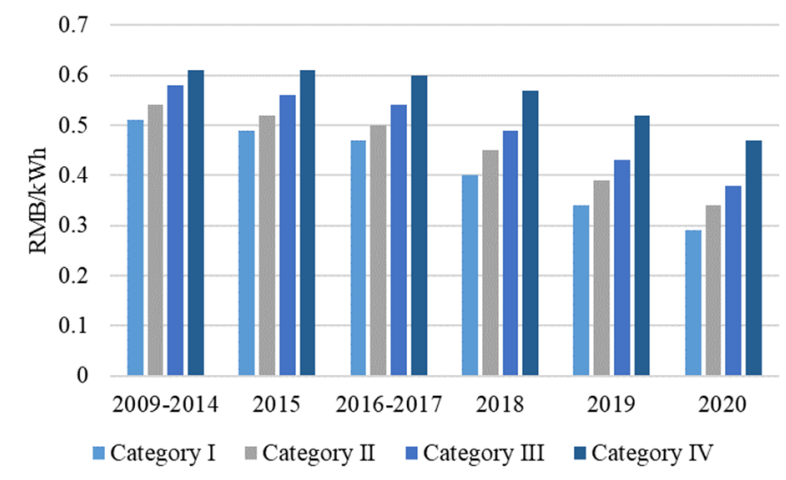

Fig2. Onshore wind feed-in tariff in China

Source: NDRC

The feed-in tariffs of onshore wind energy were adjusted five times since 2009. The trend is downward, and the goal is that the wind power should be sold to the grid with the same benchmark tariffs as coal-fired power. The feed-in tariff of offshore wind energy also has a downward trend, but in 2020 it remains $0.75 \mathrm{RMB} / \mathrm{kWh}$.

\subsection{PV}

Before 2002, all PV projects in China were demonstration projects led by the government. From 2002 to 2006, a series of financing projects were established to promote PV projects. Since 2007, the government started to approve on-grid tariffs for PV projects, ranging between 4.0 and 9.0 RMB/kWh [5]. From 2009 to 2011, several projects were approved via the concession tendering process and receive a dramatically lower tariff than before, which ranged from 0.73 to $1.15 \mathrm{RMB} / \mathrm{kWh}$. In 2011, a national wide feed-in tariff was introduced and be adjusted in the following years. The tariffs setting system of PV energy is born from the practice of wind energy.

However, due to a massive difference in the investment process for residential and commercial PV power stations, PV power's feed-in tariff system is more complicated. It needs to be categorized according to the richness of resources, and it should also consider the scales and application scenarios. As the price of PV panels is going down, more competition factors were introduced in the tariff setting, and the feed-in tariffs of PV energy will also be the same as the benchmark on-grid power tariff of the coal-fired power plant in the coming years.

\subsection{Hydropower station}

The on-grid power tariff setting mechanism for hydropower stations is similar to coal-fired power plants, but it has no general benchmark tariffs. The reason behind it is that every hydropower investment project has its condition in hydrological and geological areas. The cost of construction could have a significant difference from project to project. NDRC approves large hydropower investment projects' tariffs, and the provincial governments decides tariffs on smaller projects. But in general, on-grid power tariffs for hydropower stations are in the range of $0.2-0.3 \mathrm{RMB} / \mathrm{kWh}$, which is lower than that of the coal-fired power plant in the same region.

\section{Impact from power market reform}

Before 2015, the on-grid power tariffs were mainly regulated and determined by the NDRC and provincial development and reform commissions. Further reform in China's power industry would create fair and competitive power markets with effective and independent regulation. The functional regional electricity markets in Guangdong and some other provinces had been established to allow on-grid electricity price to be decided through bidding processes, with a ceiling to avoid excessive price hikes.

In the early phase of the power market reform, the ongrid power prices were expected to be reduced compared to the former regulated on-grid power tariffs. In Guangdong, where the new market-oriented price-setting mechanisms are being tested, the bilateral negotiation results for yearly contract 2020 show that the average price reduced by $0.0471 \mathrm{RMB} / \mathrm{kWh}$ [13]. Prices in the coming spot market for generators, even with the same technology and capacity in different places, could have a different price because of the nodal pricing mechanism. In a competitive environment, the on-grid power price would be more dynamic and related to the power supply and demand in a short time. Overall, the on-grid power prices will no longer be fixed, but depend on resource allocation, grid constrain, load change, forecast error of renewable energies, and competitor behaviours.

Based on the above analysis, the operator of generation portfolios faces three major risks and challenges. Firstly, the market-oriented prices are generally lower than the regulated prices in a short time, which brings more pressure on the downward revenues. Secondly, the 
dynamic price makes the economic evaluation more complicated. The existing power plants and the investors for new power plants need to update their evaluation model for the generation portfolio. Thirdly, some inefficient and small conventional power plants would be permanently closed due to a lack of flexibility and power market competitiveness.

After introducing the power market in China, the ongrid power tariffs will be replaced by the spot price, but it is still valuable because the long-term power contracts and prices will still reflect to the tariffs. For the generation portfolios, which have a particular function in the power industry or are built in middle-west China, the on-grid tariffs would still be used for a long time. Among all the generation technologies, the power plants with more flexibility would get a better price i.e., the gas-fired power plant and the pumped storage power plants. As the National Development and Reform Commission issued the "Guiding Opinions on Deepening the Reform of the On-grid Power Tariff Formation Mechanism for Coalfired Power Generation" on October 21, 2019, the era of benchmark power tariffs was ended. At the same time, this new guideline pointed out, that the thermal power plant should have more chance to be financed by participating in the ancillary service market and in some provinces and regions, where the coal-fired power plant has very low utilization hours, the capacity compensation mechanism or capacity market should be established to ensure the conventional power plants have an applicable financing method before the marked is fully liberalized.

\section{Conclusion}

The benchmark on-grid power tariff mechanism has been implemented for around 15 years and has played an important guiding role in China's power industry. Firstly, it secured the long-term electricity price level, which attracted more investment, and provided a price signal for investment decisions. Secondly, all the generation companies in one region have the same price for each generated power, which means that the profit level reflects the difference in cost control and operation management performance. As profit-making enterprises, generation companies were encouraged to calculate the benchmark build cost and benchmark operation cost. They have a strong motivation to reduce costs, which requires continuous improvement in management and operation efficiency. The benchmark on-grid power tariff mechanism turns the external competition for power generation into a content enhancement of management level, thereby improving the entire industry's efficiency. However, the share of different generation types in China was dramatically changed in the past years. Some problems also go with the fixed on-grid power tariffs. Firstly, the benchmark on-grid power tariffs adjusted only by policy-based mechanism, which cannot reflect the dynamic value of electricity in different time and place; Secondly, the benchmark on-grid power tariffs of all generation technologies anchor the benchmark on-grid power tariffs of coal-fired power plants. Although there is a coal-power linkage mechanism, it cannot directly transmit the change of coal price to the power price in time and reflect the cost of power generation in the entire industry. With the increase in the proportion of renewable energy in power generation, the utilization hours of traditional thermal power have gradually decreased. The price-setting system based only on the quantitative value of power could not support to cover the investment of new thermal power units, because the flexibility and the stability of thermal power plants are not taken into account in the benchmark on-grid power tariffs. Furthermore, the traditional benchmark power tariffs contain various crosssubsidies, which are not a part of the power price formed by the market mechanism.

The research has also shown that, with the gradual improvement of the ancillary service market price system, the expansion of allowable fluctuation range of spot market prices, and the introduction of a capacity compensation mechanism or even capacity market, the market will play a fundamental role in the allocation of resources in power industry. Investment in various types of power sources will be more market-oriented. Although conventional power plants with more flexibility will receive lower income from electricity market, the income from auxiliary service market and capacity market will increase. The portfolio management and trading strategy among different markets will replace the simple generation volume strategy which only aims to get more utilization hours and the new strategy will become the key to the recoup the investments of most power sources in the future.

\section{References}

1. P. L. Joskow, R. Schmalensee, Markets for Power: An Analysis of Electrical Utility Deregulation, MIT Press Books, edition 1, volume 1, (1988)

2. S. Ghosh, P. Sanyal, Product Market Competition and Upstream Innovation: Evidence from the U.S. Electricity Market Deregulation, The MIT Press Journals, pp. 237-254, (2013)

3. P. Li, Y. Wang, Q. Liu, X. Shen, K. Zhang, L. Dong, J. Yuan, Coal power overcapacity and investment bubble in China during 2015-2020, Energy Policy, pp. 136-144, (2016)

4. State Council of the People's Republic of China, Plan of Electric Industry Reform, http://www.gov.cn/zhengce/content/201709/13/content 5223177.html

5. J. Ma, On-grid electricity tariffs in China: Development, reform and prospects, Energy Policy, pp. 2633-2645, (2011)

6. State Council of the People's Republic of China, Several opinions on further deepening the reform of the power system, SC 2015, No. 9. http://www.chinanengyuan.com/news/91900.html

7. NDRC. Implementation Measures for Electricity Price Reform, NDRC 2005, No. 514, (2005), http://www.nea.gov.cn/201108/16/c_131052547.htm 
8. NDRC. Notice on further resolving electricity price contradiction and regulating electricity price management, NDRC 2004, No. 610, (2004), http://www.nea.gov.cn/2011-

08/16/c_131052531.htm

9. NDRC. Opinions on the establishment of coal and electricity price linkage mechanism, NDRC 2004, No. 2909, (2004), http://www.nea.gov.cn/201108/17/c $131054427 . \mathrm{htm}$

10. NDRC. Trial Measures for Management of Renewable Energy Power Generation Prices and Expenses Sharing, NDRC 2006, No. 7, (2006). http://www.gov.cn/ztzl/2006-

01/20/content_165910.htm

11. NDRC. Notice on Improving the Price-Setting Mechanism of Pumped Storage Power Plants, NDRC 2014, $\quad$ No. $1763 . \quad$ (2014). http://www.hydropower.org.cn/showNewsDetail.asp ?nsId $=14038$

12. DRC Zhejiang. Notice of Zhejiang Provincial Development and Reform Commission on Adjusting the On-grid Power Tariff of Gas-fired Power Plant, Zhejiang DRC 2018 No. 529. (2018). http://fzggw.zj.gov.cn/art/2018/11/7/art_1599552_30 287593.html

13. Guangdong Power Exchange Center. Notice on the release of the results of bilateral negotiations for $\begin{array}{lll}\text { yearly } & \text { contract } 2020 . & \text { (2019). }\end{array}$ https://www.sohu.com/a/359885534_99908709 